\title{
FLORA DA BAHIA: BIA KLOTZSCH E TRAGIA L. (EUPHORBIACEAE)
}

\author{
Airã de Lima Bomfim ${ }^{1}$; Daniela S. Carneiro Torres ${ }^{2}$ \\ 1. Bolsista PIBIC/FAPESB, Graduando em Bacharelado em Ciências Biológicas, Universidade Estadual de Feira de \\ Santana, e-mail: yanbomfim@ hotmail.com \\ 2. Orientador, Departamento de Ciências Biológicas, Universidade Estadual de Feira de Santana, e-mail: \\ dscarneiro@hotmail.com
}

PALAVRAS-CHAVE: Diversidade; Morfologia; Plukenetieae.

\section{INTRODUÇÃO}

Euphorbiaceae possui cerca de 300 gêneros e 6000 espécies. No Brasil, ocorrem cerca de 70 gêneros e aproximadamente 1000 espécies, representando uma das mais complexas famílias da flora brasileira (Souza \& Lorenzi, 2012). No estado da Bahia ocorrem cerca de 40 gêneros e 260 espécies (Cordeiro et al., 2016). Sendo considerada como uma família morfologicamente bem delimitada pela presença de um ovário súpero, tricarpelar e trilocular com um óvulo por lóculo (APG III 2009).

Bia é um pequeno gênero neotropical com cinco espécies (Webster 2007). Segundo Cordeiro et al. (2016) são registradas duas espécies (B. alienata Didr. e B. lessertiana Baill.) para a Bahia. Esse gênero é morfologicamente distinto de Tragia por apresentar maior número de estames (8-20) e inflorescências bifurcadas distintas, com flores estaminadas e pistiladas em diferentes eixos (Webster 2007).

Tragia reúne 125 espécies distribuídas principalmente na África e América (Webster 1994). Cordeiro et al. (2016) citam 16 espécies para o Brasil, das quais três ocorrem na Bahia (T. bahiensis Mull.Arg., T. cuneata Mull.Arg. e T. volubilis L.). O gênero é representado morfologicamente por plantas monoicas, geralmente trepadeiras com indumento de tricomas urticantes. As inflorescências são racemosas, sendo as flores estaminadas com 3-5 estames (Lucena 2009).

Este trabalho visa realizar uma revisão taxonômica dos gêneros Bia e Tragia (Euphorbiaceae) para o estado da Bahia, caracterizando-os com dados de morfologia externa e polínica, a fim de utilizar diferentes abordagens que possibilitem uma melhor delimitação das espécies, auxiliando na preservação e manutenção desses gêneros.

\section{METODOLOGIA}

Foi realizado um levantamento bibliográfico sobre Bia e Tragia, envolvendo estudos em taxonomia, morfologia, monografias e floras.

Foram analisadas ca. 150 exsicatas através de visitas aos herbários HUEFS, CEPEC e ALCB, além da consulta dos materiais tipos através de imagens digitais. As descrições foram elaboradas a partir da análise das exsicatas, sendo comparadas às obras príncipes e imagens dos tipos para uma melhor identificação. Os mapas de distribuição geográfica foram elaborados diretamente no site do Projeto. Foram feitas chaves de identificação, para os gêneros e para as espécies da Bahia, além de comentários sobre as espécies.

Para a análise polínica foram coletados botões florais em exsicatas de herbário. O processamento dos grãos de pólen para a análise em microscopia de luz seguiu a metodologia proposta por Erdtman (1960) utilizando a técnica de acetólise. 


\section{RESULTADOS E DISCUSSÃO}

Foram registradas duas espécies de Bia, B. alienata Didr., e B. lessertiana Baill., e duas espécies de Tragia, T. bahiensis Müll. Arg., e T. volubilis L, para a Bahia.

\section{Bia Klotzsch}

Ervas, trepadeiras ou lianas, volúveis, monoicas; ramos cilíndricos, glabrescentes, pilosos ou pubescentes, tricomas simples, urticantes. Folhas simples, alternas, membranáceas; actinódroma; pecioladas; limbo ovado, elíptico ou elíptico-lanceolado, 5-14 x 1-5 cm, ápice agudo ou atenuado, margem denteada ou crenada, base truncada a cordada. Inflorescências em racemos bifurcados, um estaminado e outro pistilado, axilares; raque glabra a tomentosa; flores pediceladas, solitárias. Flores estaminadas monoclamídeas, sobrepostas por uma brácteola; cálice lobado, 3-4 lobos; disco interestaminal presente, 6-9 glândulas, cilíndricas, livres; estames 9-20, filetes conados na base, anteras dorsifixas; grãos de pólen inaperturados, esferoidais, exina tectada, micro reticulada (microscopia de luz). Flores pistiladas monoclamídeas; cálice lobado, 5-6 lobos; ovário 3-locular, uniovulado, subgloboso, pubescente a tomentoso; estiletes 3, unidos em coluna e livres no ápice. Fruto cápsula, septicida loculicida, 3-mericarpos; sementes globosas, carúncula ausente.

\section{Chave para as espécies}

1. Limbo 10-14 x 3-5 cm, estames $14(-9)$. 1. Bia alienata

1'. Limbo 5-10 x 1-3 cm, estames 15-20. 2. Bia lessertiana

1.1. Bia alienata Didr., Vidensk. Meddel. Dansk Naturhist. Foren. Kjøbenhavn 9: 131. 1857.

Bia alienata é uma espécie pouco ocorrente na Bahia e difere de B. lessertiana, principalmente, por apresentar o limbo com 10-14 x 3-5 cm e 14 (-9) estames, enquanto B. lessertiana possui 5-10 x 1-3 cm e 15 a 20 estames. Morfologicamente essas espécies são muito semelhantes. Os espécimes analisados apresentaram 14 estames, sendo T.S. dos Santos 1307 o único espécime com 9 estames. Esse material estava identificado como Tragia sellowiana que atualmente é sinônimo de B. alienata. Estudos posteriores com análise de um maior número de espécimes podem auxiliar na delimitação desses táxons, já que B. alienata pode apresentar 9, 12 ou 14 estames.

No Brasil ocorre na Bahia, Distrito Federal, Mato Grosso do Sul, Minas Gerais, Paraná, Pernambuco, Santa Catarina e São Paulo. Em áreas de cerrado, floresta estacional decidual e floresta ombrófila. Coletada com flores entre novembro e janeiro.

1.2. Bia lessertiana Baill., Étude Euphorb. 502. 1858

Bia lessertiana possui mais registros de coletas do que $B$. alienata, ambas predominando em domínio da Mata Atlântica, entretanto, B. lessertiana, ocorre também na Amazônia e $B$. alienata, no Cerrado. A análise polínica não revelou caracteres diagnósticos que corroborassem para a separação dessas espécies, sendo o tamanho dos 
grãos de pólen o único caráter que difere, porém pouco empregado em delimitação de espécies, por isso seria importante o emprego de microscopia de varredura para uma melhor caracterização polínica.

No Brasil ocorre no Amapá, Bahia, Maranhão, Pará, Pernambuco. Em floresta de terra firme e floresta ombrófila. Coletada com flores durante todo o ano e frutos em março, agosto e novembro.

\section{Tragia L.}

Subarbustos, ervas, trepadeiras ou lianas, volúveis, monoicas; ramos cilíndricos, pilosos ou pubescentes; tricomas simples, urticantes. Folhas simples, alternas, membranáceas, actinódroma; pecioladas; limbo ovado ou ovado-lanceolado, 2,5-9,5 x 1-6,5 cm., ápice agudo ou atenuado, margem denteada a serreada, base truncada, obtusa subcordada ou cordada. Inflorescências em racemos, axilares, flores pistiladas proximais e estaminadas distais, raque pilosa a pubescente; flores pediceladas, solitárias. Flores estaminadas monoclamídeas, sobrepostas por uma brácteola; cálice lobado, 3 lobos; disco interestaminal ausente; estames 2-3, livres, anteras basifixas; grãos de pólen 3colpoidados, exina tectada, micro reticulada (microscopia de luz). Flores pistiladas monoclamídeas, cálice lobado, 5-6 lobos; ovário 3-locular, lóculo uniovulado, subgloboso, piloso a híspido-pubescente; estiletes 3, unidos em coluna e livres no ápice. Fruto cápsula, septicida loculicida; 3-mericarpos; columela persistente; sementes globosas, carúncula ausente.

\section{Chave para as espécies}

1. Estames 3; flores pistiladas com pedicelo $\leq 2 \mathrm{~mm}$ 1. Tragia bahiensis

1 '. Estames 2; flores pistiladas com pedicelo $\geq 5 \mathrm{~mm}$ 2. Tragia volubilis

2.1. Tragia bahiensis Müll. Arg. Linnaea 34: 182. 1865.

Tragia bahiensis possui três estames e flores pistiladas com pedicelo $\leq 2 \mathrm{~mm}$, enquanto T. volubilis, possui dois estames e $\geq 5 \mathrm{~mm}$. Além desses caracteres outros podem ser utilizados na separação desses táxons como a forma da base do limbo e o indumento do ovário, que em T. bahiensis a base é cordada e o ovário é piloso a pubescente enquanto T. volubilis truncada, obtusa ou subcordada e ovário híspido-pubescente.

No Brasil ocorre na Bahia, Ceará, Mato Grosso, Minas Gerais, Paraná, São Paulo, Rio Grande do Sul. Em áreas de caatinga, campo limpo e cerrado. Coletada com flores durante todo o ano e frutos em dezembro e abril.

\subsection{Tragia volubilis L. Sp. P1. 2: 980. 1753.}

Tragia volubilis é uma espécie bem amostrada no estado. A análise polínica não revelou caracteres diagnósticos que corroborassem para a separação das espécies de Tragia para a Bahia, necessitando da microscopia eletrônica de varredura para melhor caracterização polínica. 
No Brasil ocorre na Bahia, Rondônia, São Paulo. Em áreas de caatinga, floresta de terra firme e floresta ombrófila. Coletada com flores durante todo o ano e frutos entre dezembro e junho.

\section{CONSIDERAÇÕES FINAIS}

Bia Klotzsch e Tragia L., estão representados na Bahia por duas espécies cada (Bia alienata, B. lessertiana, Tragia bahiensis e T. volubilis), sendo os principais caracteres utilizados na delimitação das espécies de Bia o tamanho do limbo e o número de estames, enquanto que em Tragia é utilizado o número de estames e o tamanho do pedicelo da flor pistilada. A análise polínica, a partir do método da microscopia de luz, mostrou uma variação quanto a abertura e tamanho dos grãos de pólen entre os gêneros, no entanto a nível de espécies esse método não revelou caracteres diagnósticos que corroborassem para a delimitação taxonômica, sendo indicado a utilização de outras técnicas como a microscopia eletrônica de varredura (MEV). Todas as espécies analisadas neste trabalho apresentam ampla distribuição geográfica no País, mas nenhuma é endêmica. Para a Bahia, Bia lessertiana e Tragia volubilis são as espécies melhor amostradas em termo de coletas, sendo Bia alienata a espécie com menos registros para o Estado. Este estudo contribui para o conhecimento do grupo na Flora do Brasil e para a taxonomia dos gêneros.

\section{REFERÊNCIAS}

APG III. 2009. An update of the Angiosperm Phylogeny Group classification for the orders and families of flowering plants: APG III. Botanical Journal of the Linnean Society Of London 161: 105-121.

Cordeiro, I.,Secco, R.,Cardiel, J.M.,Steinmann, V.,Caruzo, M.B.R.,Riina, R.,Lima, L.R. de,Maya-L., C.A.,Berry, P.,Carneiro-Torres, D.S.,O.L.M. Silva,Sales, M.F.d.,Silva, M.J.da,Sodré, R.C.,Martins, M.L.L.,Pscheidt, A.C.,Athiê-Souza, S.M.,Melo, A.L.d.,Oliveira, L.S.D.,Paula-Souza, J.,Silva, R.A.P. 2016. Euphorbiaceae in Lista de Espécies da Flora do Brasil. Jardim Botânico do Rio de Janeiro. Disponivel em: 〈http://floradobrasil.jbrj.gov.br/jabot/floradobrasil/FB113>.

Erdtman, G., 1960. Pollen morphology and plant taxonomy Angiosperms. A revised description. Seven. Bot. Tidskr., 54:561-564.

Lucena, M. F. A. 2009. Diversidade de Euphorbiaceae (s.1) no Nordeste do Brasil. Tese de doutorado apresentada na Universidade Federal do Pernambuco. Centro de Ciências Biológicas. Programa de Pós-graduação em Biologia Vegetal, 2009.

Souza, C. V. \& Lorenzi, H. 2012. Botânica Sistemática: guia ilustrativo para identificação das famílias de Angiospermas da flora brasileira, baseado em APG II. Nova Odessa, SP: Instituto Plantarum.

Webster, G. L. 1994. Synopsis of the genera and suprageneric taxa of Euphorbiaceae. Annals of Missouri Botanical Garden 81: 33-144.

Webster, G. L. 2007. TAXONOMIC AND NOMENCLATURAL CHANGES IN AMERICAN EUPHORBIACEAE SENSU LATO. Contr. Univ. Michigan Herb. 25: 235-239. 